\title{
PENGARUH TOTALITAS KERJA DAN MODAL PSIKOLOGIS TERHADAP KEPUASAN KERJA DRIVER GOJEK DI JAKARTA SELATAN
}

\author{
Ardisa Citradewi \\ ardisacitra@yahoo.com \\ Anggota HIMPSI Provinsi Jakarta
}

\author{
J. P. Soebandono \\ jsoebandono@gmail.com \\ Fakultas Psikologi UIN Syarif \\ Hidayatullah Jakarta
}

\begin{abstract}
This study aims to determine the effect of the work engagament and psychological capital to job satisfaction drivers gojek. Through this research is expected to find out how far the influence of the totality of work and psychological capital on the drivers of gojek. This research uses quantitative approach with regression analysis method, and validation test of construct using Confirmation Factor (CFA) technique. The sample numbered 175 drivers gojek. The sample of research was determined by using non probability sampling technique. The data collection instrument using Job Satisfaction Survey (JSS) developed by Spector, Utrecht Work Engagement Scale (UWES) was developed by Schaufeli and Bakker and Psychological Capital Questionner (PCQ-24) developed by Luthans, Avolio, et al., 2007. The results of this study indicate that there is a significant influence of the variable influence of work engagement and psychological capital with a significance value of 0.000 or $p<0.05$ to job satisfaction. So the nil hypothesis (Ho) that exist in the major hypothesis in this study was rejected. The result of the test of the minor hypothesis examining the influence of $7 \mathrm{IV}$, there are two nil hypothesis (Ho) rejected, it means that there are two IV that have significant effect on job satisfaction, the absorption and resilience variable, while the vigor variable, dedication, self efficacy, optimism and hope effect on job satisfaction.
\end{abstract}

Key Word : Job Satisfaction, Work Engagement, Psychological Capital

\begin{abstract}
Abstrak
Penelitian ini bertujuan untuk mengetahui pengaruh totalitas kerja dan modal psikologis terhadap kepuasan kerja driver gojek. Melalui penelitian ini diharapkan dapat mengetahui signifikansi pengaruh totalitas kerja dan modal psikologis pada driver gojek. Populasi yang diteliti dalam penelitian ini driver gojek. Sampel dalam penelitian berjumlah 175 responden. Instrumen pengumpulan data menggunakan Job Satisfaction Survey (JSS) yang dikembangkan oleh Spector, Utrecht Work Engagement Scale (UWES) dikembangkan oleh Schaufeli dan Bakker dan Psychological Capital Questionner (PCQ-24) dikembangkan oleh Luthans, Avolio, et al., 2007. Penelitian ini menggunakan pendekatan kuantitatif dengan metode analisis regresi, serta pengujian validatas konstruk menggunakan teknik Analisa Faktor Konfirmatori (CFA). Sampel penelitian ditentukan dengan menggunakan teknik non probability sampling. Hasil penelitian ini menunjukkan bahwa terdapat pengaruh yang signifikan dari variabel pengaruh totalitas kerja dan modal psikologis dengan nilai signifikansi sebesar 0.000 atau $\mathrm{p}<0.05$ terhadap kepuasan kerja. Jadi hipotesis nihil (Ho) yang ada pada hipotesis mayor dalam penelitian ini ditolak. Hasil uji hipotesis minor yang menguji pengaruh $7 \mathrm{IV}$, ada dua hipotesis nihil (Ho) yang ditolak, artinya ada dua IV yang berpengaruh signifikan terhadap kepuasan kerja, yaitu variabel absorption dan resiliensi, sedangkan variabel vigor, dedication, efikasi diri, optimis dan harapan tidak berpengaruh terhadap kepuasan kerja
\end{abstract}

Kata kunci : Kepuasan Kerja, Totalitas Kerja, Modal Psikologi

Diterima: 02 Juli 2017 Direvisi: 10 Agustus 2017 Disetujui: 20 September 2017 


\section{PENDAHULUAN}

Dewasa ini transportasi adalah hal yang penting bagi masyarakat, seperti angkutan umum, taxi, ojek dan sebagainya. Adanya sarana transportasi di Indonesia dapat memudahkan kelangsungan hidup setiap manusia dan masyarakat akan lebih mudah untuk melakukan aktifitas keseharian. Dari sekian banyaknya transportasi di Indonesia, masyarakat umum lebih memilih untuk menggunakan motor karena kemacetan yang semakin memuncak di Jakarta dan masyarakat dapat memanfaatkan motor sebagai mata pencaharian (Aryatama, 2016). Semakin lama ojek mulai berkembang, lalu di dukung oleh teknologi yang semakin berkembang pesat dan banyak orang cerdas yang dapat menemukan hal baru untuk menciptakan lapangan kerja bagi masyarakat. Pada tahun 2010 telah berdirinya PT. Gojek Indonesia. PT. Gojek Indonesia didirikan oleh Nadiem Karim dan Michaelangelo Moran. Perusahaan ini bergerak di bidang jasa layanan transportasi sebagai perantara yang menghubungkan antara para pengendara ojek dengan pelanggan. PT. Gojek merupakan perusahaan teknologi berjiwa sosial yang bertujuan untuk meningkatkan kesejahteraan pekerja di berbagai sektor formal di Indonesia (www.go-jek.com)

Pada Januari 2015, perusahaan meluncurkan aplikasi mobile GO-JEK berbasis location-based search untuk telepon genggam berbasis android dan iOS (apple). Jasa dan layanan GO-JEK berkembang tidak hanya sebagai transportasi orang (transport), tetapi juga dapat digunakan sebagai pengantar barang, dokumen, ataupun paket (instant courier), sebagai mitra perusahaan online maupun offline yang membutuhkan pengantaran pada hari yang sama (shopping), bahkan yang terbaru dapat digunakan sebagai pengantar makanan yang dipesan (food delivery) (www.go-jek.com).Salah satu kebijakan yang diterapkan oleh PT. Gojek Indonesia adalah tentang sistem performa driver (Aditya Panji, 2015).

Tujuan kebijakan sistem performa yang telah dibuat adalah (1) untuk meningkatkan semangat para driver dalam menjalankan tugasnya, (2) mengurangi kemungkinan terjadinya penolakan order oleh pengemudi dan (3) peningkatan kepuasan pelanggan karena order yang diinginkan terpenuhi. Kebijakan sistem performa yang diterapkan untuk driver gojek dapat membuat driver gojek lebih semangat. Jika driver gojek dapat mematuhi peraturannya, driver akan mendapatkan reward atau bonus lebih yang diberikan oleh PT. Gojek.

Tetapi pada bulan agustus 2016 PT. Gojek Indonesia merubah kebijakan sistem performa yang membuat para driver gojek menganggapnya sebagai beban karna menurut driver perubahan nya merugikan, sedangkan kebijakan sistem performa di kota-kota lainnya sudah dihapuskan. Driver gojek juga merasakan ketidakpuasan terhadap manajemen PT. Gojek Indonesia sehingga membuat para driver gojek di Jakarta melakukan demo pada PT. Gojek Indonesia. Alasan PT. Gojek merubah sistem performa adalah untuk pelanggan yang akan lebih mudah mendapatkan driver saat melakukan pemesanan, berdampak pada driver gojek yang nanti nya akan mendapat upah lebih dan juga keberlanjutan bisnis pada PT. Gojek Indonesia (Jessica Carina, 2016)

Berdasarkan hasil wawancara yang dilakukan oleh penulis kepada empat driver gojek mengenai puas atau tidaknya driver gojek dalam melakukan pekerjaan nya yaitu rata-rata tanggapan driver gojek adalah driver kurang puas terhadap 
pekerjaannya, karena ada beberapa hal yang menurut driver gojek menghambat untuk mendapatkan penghasilan. Di antaranya itu mengenai applikasi yang sering erorr sehingga menyebabkan banyaknya pelanggan membatalkan pemesanan gojek dan membuat rating driver menurun, lalu banyaknya promo yang sudah ditentukan oleh PT. Gojek bertujuan untuk membuat pelanggan semakin banyak untuk memesan gojek tetapi hal itu membuat driver gojek merasa tidak puas dikarenakan tidak seimbang antara penghasilan yang didapat dengan jarak tempuh yang jauh.

Berdasarkan fenomena yang sudah dijelaskan, dapat dikatakan driver gojek secata tidak langsung merasa ketidakpuasan terhadap manajamen perusahaan dan pekerjaan yang dilakukan yaitu sebagai driver. Driver Gojek merasakan ketidakpuasan dalam menjalankan pekerjaanya karena perubahan kebijakan sistem. Kepuasaan kerja merupakan salah satu faktor yang sangat penting untuk mendapatkan hasil kerja yang optimal. Setiap individu mempunyai tingkat kepuasan yang berbeda-beda sesuai dengan sistem nilai yang berlaku pada dirinya. Semakin banyak aspek yang sesuai dalam pekerjaannya dengan keinginan individu tersebut maka semakin tinggi tingkat kepuasan yang dirasakan dan begitu juga sebaliknya. Jika individu merasakan kepuasan dalam pekerjaannya tentunya akan berupaya semaksimal mungkin dengan segala kemampuan yang dimilikinya untuk menyelesaikan pekerjaannya (Sinambela Poltak, 2016).

Kepuasan kerja dapat mengacu pada bagaimana orang-orang merasakan sifat dari pekerjaan itu sendiri dan bagaimana orang merasakan situasi di luar dari pekerjaan itu sendiri atau lingkungan pekerjaannya (Spector, 1997). Menurut Gilmer dalam As'ad (2004) terdapat 10 faktor yang mempengaruhi kepuasan kerja yaitu kesempatan untuk maju, keamanan kerja, gaji, perusahaan dan manajemen, pengawasan, faktor intrinsik dari pekerjaan, kondisi kerja, aspek sosial, komunikasi dan fasilitas.

Berdasarkan hasil penelitian terdahulu yang dapat mempengaruhi kepuasan kerja adalah totalitas kerja dan modal psikologis, namun yang cukup besar berpengaruh adalah totalitas kerja. Totalitas kerja merupakan keadaan mental seseorang terkait dengan pekerjaannya yang bersifat positif dan penuh yang ditandai oleh vigor, dedication dan absorption (Schaufeli, dkk., 2002), totalitas kerja juga dapat dikatakan menjadi sisi positif psikologis manusia.

Totalitas kerja dapat dijelaskan bahwa terdapat energi yang tinggi dan ketahanan mental terhadap pekerjaan dan tetap bertahan walaupun mengalami kesulitan yang dialami oleh driver, yaitu sulitnya mendapatkan pelanggan dan waktu kerja yang berjam-jam bagi driver, tetapi driver tetap memiliki dedikasi yang tinggi dengan pekerjaannya karena ingin mendapatkan penghasilan yang cukup dan dapat mencapai tujuan. Lalu terdapat rasa bangga pada pekerjaan yang dilakukan, antusias terhadap pekerjaan maupun tantangan yang ada didalam perkejaan, adanya rasa bahagia dengan pekerjaan yang dijalankan dan fokus pada pekerjaan. Driver gojek dapat dikatakan memiliki totalitas terhadap pekerjaannya ketika driver mampu memenuhi peraturan PT. Gojek Indonesia, mampu membuat puas pelanggan terhadap layanan yang telah diberikan seperti memberikan masker kepada pelanggan, memberikan helm dan dengan adanya masalah di PT. 
Gojek Indonesia, driver lebih semangat dan fokus menjalankan pekerjaannya agar tujuan yang diharapkan tercapai.

Terdapat faktor-faktor internal yang mempengaruhi kepuasan kerja, salah satunya modal psikologis. Menurut Luthans (2011) psychological capital atau modal psikologis sebagai keadaan perkembangan psikologis seseorang yang merupakan kemampuan untuk bertahan dan maju ketika dihadapkan pada suatu masalah serta ditandai oleh : 1) percaya diri (self-efficacy atau confidance) untuk menyelesaikan pekerjaan dengan baik, 2) memiliki pengharapan positif (optimism) tentang keberhasilan saat ini dan di masa yang akan datang, 3) tekun dalam berharap (hope) untuk berhasil dalam mencapai tujuan pekerjaan 4) tabah dalam menghadapi berbagai permasalahan (resiliency) hingga mencapai keberhasilan (Luthans, Youssef \& Avolio, 2007).

Perubahan sistem performa merupakan masalah bagi para driver gojek, adanya perubahan peraturan membuat driver menjadi lebih lama untuk bekerja agar mendapatkan bonus, maka dari itu resiliensi sangat dibutuhkan pada diri driver agar mampu menghadapi masalah yang ada. Berdasarkan hasil wawancara dari beberapa para driver Gojek mengatakan bahwa mereka cenderung putus asa dengan perubahan sistem performa dari PT. Gojek Indonesia, para driver Gojek tidak tahu akan bekerja dimana lagi kalau mereka tidak bekerja sebagai driver gojek, dan para driver gojek juga sangat mengharapkan kepada PT. Gojek Indonesia untuk menghapuskan kebijakan sistem performa. Tetapi driver gojek yang lain berpendapat dengan adanya sistem performa ini membuat para driver menjadi lebih semangat dan membuat lebih rajin dalam bekerja.

Berdasarkan fenomena yang telah dijelaskan, maka penting untuk mengetahui faktor-faktor apa saja yang mempengaruhi kepuasan kerja driver Gojek di Jakarta, sehingga penulis tertarik untuk membuat penelitian yang berjudul " Pengaruh Totalitas Kerja dan Modal Psikologis terhadap Kepuasan Kerja Driver Go-Jek di Jakarta Selatan".

\section{TEORI}

\section{Kepuasan Kerja}

Dalam penelitian ini menggunakan definisi yang dikemukakan oleh Spector (1997) yang mengemukakan bahwa kepuasan kerja merupakan variabel sikap yang mendefinisikan bagaimana perasaan evaluative individual mengenai pekerjaannya, baik secara keseluruhan maupun dari berbagai aspek pekerjaannya. Perasaan tersebut berkisar antara kesukaan atau kepuasaan terhadap pekerjaannya. Faktorfaktor yang mempengaruhinya antara lain yaitu: faktor individual, faktor sosial, dan faktor utama dalam pekerjaan meliputi upah, pengawasan, ketentraman kerja, kondisi kerja, dan kesempatan untuk maju. Sedangakan dimensi kepuasan kerja meliputi: gaji, promosi. Supervise, tunjangan penghargaan dari perusahaan, prosedur kerja, rekan kerja, sifat pekerjaan, komunikasi.

\section{Totalitas Kerja}

Schaufeli et al. (2014) yang mengusulkan definisi totalitas kerja adalah sebagai keadaan positif, kepuasan,yang berhubungan dengan pikiran dalam bekerja dan ditandai oleh vigor, dedication, dan absorption. Vigor mengacu ke tingkat energy 
yang tinggi dan ketahanan mental saat bekerja, sedangkan dedication mengacu pada keadaan sedang sangat terlibat dalam pekerjaan seseorang serta mengalami rasa penting, antusias, dan tantangan. Absorption ditandai dengan sepenuhnya terkonsentrasi dan bahagia asyik dalam pekerjaan, seperti waktu yang berlalu dengan cepat. Dimensi totalitas kerja menurut Schaufeli et.al (2004) diantaranya: vigor, dedication, absorption.

\section{Kesiapan Dalam Menghadapi Perubahan}

Kesiapan dalam menghadapi perubahan merupakan keyakinan karyawan bahwa organisasi mampu melaksanakan perubahan yang diusulkan, perubahan yang dilakukan sesuai dengan organisasi, para pemimpin berkomitmen untuk perubahan yang diusulkan, dan perubahan yang diusulkan bermanfaat bagi anggota organisasi sebagaimana yang diungkapkan oleh Holt, Armenikes, Field \& Haris (2007).

\section{Modal Psikologis}

Modal psikologis merupakan kapasitas psikologis positif yang dimiliki oleh setiap individu yang berguna dalam membantu individu untuk dapat berkembang, yang meliputi kepercaya diri untuk menyelesaikan pekerjaan, memiliki pengharapan positif tentang keberhasilan saat ini dan dimasa yang akan datang, tekun dalam berharap untuk berhasil, dan ketahanan dalam menghadapi berbagai permasalahan dalam mencapai sukses sebagaimana diungkapkan oleh Luthans, Youssef, dan Avalio (2007). Berdasarkan definisi modal psikologis menurut Luthans et al (2007) terdapat empat komponen modal psikologis yang menandai bahwa seorang individu telah mencapai kondisi psikologi yang positif. Komponen tersebut adalah efikasi diri, harapan, resiliensi dan optimis.

\section{METODE PENELITIAN}

\section{Populasi, sampel dan teknik pengambilan sampel}

Populasi yang akan diteliti dalam penelitian ini adalah driver gojek di Jakarta. Dari populasi yang ada yaitu 100.000 driver gojek, penulis megambil 200 driver gojek di Jakarta Selatan sebagai sampel, tetapi hanya ada 175 kuesioner yang layak untuk diolah. Metode dalam penelitian ini adalah non-probability sampling, artinya peluang terpilihnya dari setiap responden anggota populasi tidak diketahui. Teknik yang digunakan yaitu accidental sampling. Penulis memberikan kuesioner kepada responden yaitu driver gojek, sebelumnya penulis menanyakan kesedian responden untuk mengisi kuesioner. Jika responden bersedia, penulis memberikan instruksi agar mempermudah responden dalam pengisisan.

\section{Instrumen penelitian}

Penelitian ini terdiri dari beberapa variabel yaitu kepuasan kerja, vigor, dediation, absorption, efikasi diri, harapan, optimis dan resiliensi ditetapkan sebagai independent variable. Kepuasan kerja ditentukan sebagai dependent variable pada penelitian ini. Alat pengumpul data dalam penelitian ini yaitu kuesioner berupa skala likert. Skala yang digunakan dalam penelitian ini meliputi modifikasi Job 
Statisfaction Survey (JSS). JSS merupakan format yang paling popular untuk skala kepuasan kerja dan instrument ini sudah teruji secara baik pada penelitianpenelitian terdahulu. JSS dibuat relative mudah untuk dimodifikasi. JSS menilai 9 dimensi kepuasan kerja diantaranya (gaji, promosi, supervise, tunjangan, penghargaan prosedur operasional, rekan kerja, sifat kerja, dan komunikasi). Skala JSS berisi 36 item menggunakan format skala rating yang dijumlahkan.

Untuk alat ukur Totalitas Kerja pada penelitian ini menggunakan Utrecht Work Enagegement Scale (UWES) dikembangkan oleh Schaufeli dan Bakker (2003). Skala UWES memiliki 17 item pernyataan yang terdiri dari 3 dimensi yaitu 6 item vigor, 5 item dedication, dan 6 item absorption. Skala ini yang akan digunakan peneliti dalam melakukan penelitian karena mencakup dimensi dari totalitas kerja. Selain itu, alat ukur ini lebih sering digunakan dalam beberapa penelitianpenelitian sebelumnya dan telah teruji secara baik.

Penulis menggunakan satu alat ukur yaitu pengukuran modal psikologis dilakukan dengan menggunakan alat ukur PCQ-24 (Psychological Capital Questionner). Alat ukur ini memiliki 24 item yang terdiri dalam 4 komponen yaitu efikasi diri, optimism, harapan, dan resiliensi.

\section{HASIL PENELITIAN}

\section{Besaran Muatan Independent Variable terhadap Dependent Variable}

Hasil uji hipotesis analisis regresi berganda dapat dilihat pada tabel 1.

\section{Tabel 1}

Anova Pengaruh Keseluruhan Independent Variable terhadap Dependent Variable

\begin{tabular}{ccccc}
\hline Model & R & R Square & Adjusted R Square & Std. Error of the Estimate \\
\hline 1 & $.388^{\mathrm{a}}$ & .150 & .115 & 9.40874 \\
\hline
\end{tabular}

Dari tabel 1, dapat dilihat bahwa perolehan $\mathrm{R}$ square sebesar 0,150 atau $15 \%$, artinya kontribusi varians dari kepuasan kerja yang dijelaskan oleh vigor, dedication, absorption, efikasi diri, harapan, optimis dan resiliensi adalah sebesar $15 \%$, sedangkan $85 \%$ sisanya dipengaruhi oleh variabel lain diluar penelitian.

Langkah kedua penulis melihat apakah seluruh independent variabel (IV) berpengaruh secara signifikan terhadap dependent variabel (DV), yaitu kepuasan kerja. Adapun hasilnya dapat dilihat pada tabel 2.

TABEL 2

Tabel Anova

\begin{tabular}{llccccc}
\hline & Model & Sum of Squares & df & Mean Square & F & Sig. \\
\hline \multirow{3}{*}{1} & Regression & 2616.428 & 7 & 375.775 & 4.222 & $.000^{b}$ \\
& Residual & 14783.572 & 167 & 88.524 & & \\
& Total & 17400.000 & 174 & & & \\
\hline
\end{tabular}

a. Dependent Variable: kepuasankerja

b. Predictors: (Constant), resiliensi, optimis, vigor, efikasidiri, harapan, absorption, dedication 
Berdasarkan pada tabel 2, jika dilihat pada kolom sig diketahui bahwa nilai signifikan lebih kecil ( $\operatorname{sig}<0.05$ ), maka hipotesis nihil yang menyatakan tidak ada pengaruh yang signifikan dari vigor, dedication, absorption, efikasi diri, harapan, optimis dan resiliensi terhadap kepuasan kerja ditolak, artinya terdapat pengaruh yang signifikan dari vigor, dedication, absorption, efikasi diri, harapan, optimis dan resiliensi terhadap kepuasan kerja.

Langkah ketiga adalah menjawab hipotesis minor, yaitu melihat nilai signifikan atau tidaknya koefisien regresi dari masing-masing independent variabel (IV). Apabila nilai independent variabel (IV) signifikansi yang terdapat pada kolom sig menunjukan angka dibawah 0.05 , maka koefisien regresi yang dihasilkan signifikan pengaruhnya terhadap dependent variabel (DV) dan sebaliknya. Adapun hasilnya dapat dilihat pada tabel 3.

Tabel 3

Tabel Koefisien Regresi

\begin{tabular}{lccccc}
\hline Model & \multicolumn{2}{c}{$\begin{array}{c}\text { Unstandardized } \\
\text { Coefficients }\end{array}$} & $\begin{array}{c}\text { Standardized } \\
\text { Coefficients }\end{array}$ & T & Sig. \\
\cline { 2 - 4 } & $\mathbf{B}$ & Std. Error & Beta & & \\
\hline (Constant) & 33.018 & 5.616 & & 5.879 & .000 \\
Vigor & -.017 & .091 & -.017 & -.187 & .852 \\
Dedication & .020 & .100 & .020 & .197 & .844 \\
1 Absorption & .202 & .098 & .202 & 2.050 & $.042^{*}$ \\
Efikasi diri & .165 & .089 & .165 & 1.860 & .065 \\
Harapan & .154 & .086 & .154 & 1.791 & .075 \\
Optimis & .087 & .080 & .087 & 1.096 & .275 \\
Resiliensi & -.271 & .086 & -.271 & -3.137 & $.002^{*}$ \\
\hline
\end{tabular}

a. Dependent Variable: kepuasan kerja

Berdasarkan tabel 3 dapat dipaparkan persamaan regresi sebagai berikut:

Kepuasan kerja $=33.018-0.017$ vigor +0.020 dedication +0.202 absorption $^{*}+$ 0.165 efikasi diri +0.154 harapan +0.087 optimis -0.271 resiliensi*

\section{Vigor}

Diperoleh nilai koefisien regresi sebesar -0.017 dengan nilai signifikansi 0.852 (sig $>0.05$ ). Dari hasil tersebut menunjukkan bahwa variabel vigor berpengaruh tetapi tidak signifikan terhadap kepuasan kerja.

\section{Dedication}

Diperoleh nilai koefisien sebesar 0.020 dengan nilai signifikansi 0.844 (sig> 0.05). Dari hasil tersebut menunjukkan bahwa variabel dedication berpengaruh tetapi tidak signifikan terhadap kepuasan kerja.

\section{Absorption}

Diperoleh nilai koefisien sebesar 0.202 dengan nilai signifikansi 0.042 (sig <0.05).

Dari hasil tersebut menunjukkan bahwa variabel absorption berpengaruh secara 
signifikan dan mengarah positif terhadap kepuasan kerja. Artinya semakin tinggi absorption maka semakin tinggi juga kepuasan kerja.

\section{Efikasi Diri}

Diperoleh niai koefisien sebesar 0.165 dengan nilai signifikansi 0.065 (sig > 0.05). Dari hasil tersebut menunjukkan bahwa variabel efikasi diri berpengaruh tetapi tidak signifikan terhadap kepuasan kerja.

\section{Harapan}

Diperoleh nilai koefisien sebesar 0.154 dengan nilai signifikansi 0.075 (sig > 0.05). Dari hasil tersebut menunjukkan bahwa variabel harapan berpengaruh tetapi tidak signifikan terhadap kepuasan kerja.

\section{Optimis}

Diperoleh nilai koefisien sebesar 0.087 dengan nilai signifikansi 0.275 (sig $>0.05$ ). Dari hasil tersebut menunjukkan bahwa variabel optimis berpengaruh tetapi tidak signifikan terhadap kepuasan kerja.

7. Resiliensi

Diperoleh nilai koefisien sebesar -0.271 dengan nilai signikansi $0.002($ sig<0.05). Dari hasil tersebut menunjukkan bahwa variabel resiliensi berpengaruh signifikan dan mengarah negatif terhadap kepuasan kerja. Artinya semakin tinggi resiliensi maka semakin rendah kepuasan kerja.

\section{Proporsi Varian}

Penulis ingin mengetahui bagaimana proporsi varian dari masing-masing independent variabel (IV) terhadap kepuasan kerja. Besarnya proporsi varian pada kiepuasan kerja dapat dilihat pada tabel 4.

Berdasarkan tabel 4 dapat dijelaskan sebagai berikut:

1. Variabel vigor memberikan sumbangan sebesar 1,7 \% dalam varian kepuasan kerja. Sumbangan tersebut tidak signifikan secara statistik dengan $\mathrm{F}=3.002$, $\mathrm{df} 1=1, \mathrm{df} 2=173$ dan sig $\mathrm{F}$. change $=0.085$.

2. Variabel dedication memberikan sumbangan sebesar $0.5 \%$ dalam varian kepuasan kerja. Sumbangan tersebut tidak signifikan secara statistik dengan $\mathrm{F}$ $0.837, \mathrm{df} 1=1, \mathrm{df} 2=172$ dan sig $\mathrm{F}$. change $=0.361$.

3. Variabel absorption memberikan sumbangan sebesar $2.9 \%$ dalam varian kepuasan kerja. Sumbangan tersebut signifikan secara statistik dengan $\mathrm{F}=$ $5.285, \mathrm{df} 1=1, \mathrm{df} 2=171$ dan sig $\mathrm{F}$. change $=0.023$.

4. Variabel efikasi diri memberikan sumbangan sebesar $2.4 \%$ dalam varian kepuasan kerja. Sumbangan tersebut signifikan secara statistik dengan $\mathrm{F}=$ 4.468, $\mathrm{df} 1=1, \mathrm{df} 2=170$ dan sig $\mathrm{F}$. change $=0.036$.

5. Variabel harapan memberikan sumbangan sebesar $2.3 \%$ dalam varian kepuasan kerja. Sumbangan tersebut signifikan secara statistik dengan $\mathrm{F}=$ 4.356, df1=1, df2= 169 dan sig $F$. change $=0.038$.

6. Variabel optimis memberikan sumbangan sebesar $0.2 \%$ dalam varian kepuasan kerja. Sumbangan tersebut tidak signifikan secara statistik dengan $\mathrm{F}=0.306, \mathrm{df} 1=1, \mathrm{df} 2=168$ dan sig $\mathrm{F}$. change $=0.581$. 
7. Variabel resiliensi memberikan sumbangan sebesar $5.0 \%$ dalam varian kepuasan kerja. Sumbangan tersebut signifikan secara statistik dengan $\mathrm{F}=$ 9.838, df1 $=1$, df2 $=167$ dan sig $F$. change $=0.002$.

Urutan IV yang signifikan memberikan sumbangan dari terbesar hingga yang terkecil adalah variabel resiliensi dengan $\mathrm{R}$ change $5.0 \%$ dan variabel harapan dengan $\mathrm{R}$ change $2,3 \%$.

\section{Tabel 4}

Proporsi Varians

\begin{tabular}{|c|c|c|c|c|c|c|c|c|c|}
\hline \multirow[t]{2}{*}{ Model } & \multirow[t]{2}{*}{$\mathbf{R}$} & \multirow{2}{*}{$\begin{array}{l}R \\
\text { Square }\end{array}$} & \multirow{2}{*}{$\begin{array}{l}\text { Adjusted } \\
R \text { Square }\end{array}$} & \multirow{2}{*}{$\begin{array}{l}\text { Std. Error } \\
\text { of the } \\
\text { Estimate }\end{array}$} & \multicolumn{5}{|c|}{ Change Statistics } \\
\hline & & & & & $\begin{array}{l}R \text { Square } \\
\text { Change }\end{array}$ & F Change & $d f 1$ & $d f 2$ & $\begin{array}{l}\text { Sig. } F \\
\text { Change }\end{array}$ \\
\hline 1 & $.131^{\mathrm{a}}$ & .017 & .011 & 9.94296 & .017 & 3.002 & 1 & 173 & .085 \\
\hline 2 & $.148^{\mathrm{b}}$ & .022 & .010 & 9.94764 & .005 & .837 & 1 & 172 & .361 \\
\hline 3 & $.226^{\mathrm{c}}$ & .051 & .034 & 9.82599 & .029 & 5.285 & 1 & 171 & .023 \\
\hline 4 & $.275^{\mathrm{d}}$ & .075 & .054 & 9.72785 & .024 & 4.468 & 1 & 170 & .036 \\
\hline 5 & $.314^{\mathrm{e}}$ & .099 & .072 & 9.63323 & .023 & 4.356 & 1 & 169 & .038 \\
\hline 6 & $.317^{\mathrm{t}}$ & .100 & .068 & 9.65306 & .002 & .306 & 1 & 168 & .581 \\
\hline 7 & $.388^{g}$ & .150 & .115 & 9.40874 & .050 & 9.838 & 1 & 167 & .002 \\
\hline
\end{tabular}

\section{KESIMPULAN DAN SARAN}

\section{Kesimpulan}

Terdapat pengaruh yang signifikan antara variabel totalitas kerja (vigor, dedication dan absorption) dan modal psikologis (efikasi diri, harapan, optimis dan resiliensi) terhadap kepuasan kerja pada driver gojek. Kemudian dari tujuh variabel yang diuji terdapat dua yang dinyatakan signifikan yang mempengaruhi kepuasan kerja driver gojek, yaitu absorption dan resiliensi. Sedangkan variabel vigor, dedication, efikasi diri, harapan dan optimis tidak memberikan pengaruh yang signifikan. Sehingga hipotesis minor yang menyatakan kelima variabel tersebut memberikan pengaruh terhadap kepuasan kerja driver gojek ditolak. Apabila dilihat dari signifikansi berdasarkan tabel 4, sumbangan kontribusi pada masing-masing independent variabel (IV) terdapat empat variabel yang signifikan memberikan sumbangan dengan nilai terbesar sampai terkecil yaitu variabel resiliensi, absorption, efikasi diri dan harapan. Artinya terdapat tiga variabel independen yang tidak signifikan yaitu vigor, dedication dan optimis.

\section{Diskusi}

Hasil pengujian hipotesis yang telah dibahas pada bab 4, diperoleh hasil yaitu terdapat pengaruh yang signifikan antara totalitas kerja (vigor, dedication dan absorption) dan modal psikologis (efikasi diri, harapan, optimis dan resiliensi) terhadap kepuasan kerja dengan signifikansi sebesar 0.000 dan nilai kontribusi independent variabel (IV) terhadap dependent variabel (DV) sebesar 0.150 atau $15 \%$. Hasil yang telah didapatkan menunjukkan bahwa totalitas kerja dan modal psikologis memiliki pengaruh yang signifikan terhadap kepuasan kerja driver gojek sebesar $15 \%$ dan sisa nya $85 \%$ yang dipengaruhi oleh variabel lain diluar penelitian ini. 
Hasil penelitian berdasarkan koefisien regresi pada masing-masing independent variabel (IV) menunjukkan bahwa terdapat pengaruh yang signifikan resiliensi dan absorption terhadap kepuasan kerja. Sedangkan variabel vigor, dedication, efikasi diri, harapan dan optimis tidak memiliki pengaruh yang signifikan terhadap kepuasan kerja.

Berdasarkan penelitian terdahulu telah ditemukan bahwa totalitas kerja berpengaruh positif dan signifikan terhadap kepuasan kerja. Penelitian Maharaj A (2014), mengatakan penelitian nya yang berjudul "Work Engagjement, Intrinsic Motivation and Job Satisfaction among Employees of a Diamond Mining Comoany in Zimbabwe" menunjukkan adanya hubungan yang signifikan antara kepuasan kerja dan totalitas kerja serta antara kepuasan kerja dan motivasi intrinsik. Dengan adanya motivasi didalam pekerjaan dan diri driver gojek dapat meningkatkan tingkat kepuasan pada pekerjaan yang dilakukan.

Kalvina (2016) dalam penelitiannya yang berjudul "Exploring the Relationship between Job Satisfaction, Work Engagement and Loyalty of Academic Staff" menyatakan bahwa hasil penelitiannya signifikan antara totalitas kerja dengan kepuasan kerja. Semakin merasa totalitas akan pekerjaannya, tingkat kepuasan kerja pada driver gojek juga akan semakin tinggi dan driver merasa bangga juga dengan pekerjaan yang dilakukannya. Berbeda dengan penelitian sebelumnya, yakni terdapat penelitian yang mengatakan bahwa totalitas kerja tidak berdampak positif dan signifikan terhadap kepuasan kerja, karena individu mungkin merasa puas dengan pekerjaannya, tetapi kepuasan yang dirasakannya tidak bermakna (Malhotra Shweta). Pada hasil penelitian ini dimensi vigor dan dedication dari variabel totalitas kerja memiliki hasil yang tidak signifikan terhadap kepuasan kerja. Tidak signifikannya variabel vigor dan dedication bisa terjadi karena kurangnya rasa motivasi bekerja pada diri individu dan kurangnya dedikasi yang tinggi kepada perusahaan maupun reward yang diberikan oleh perusahaan. Hasil pada penelitian ini berbeda dengan penelitian terdahulu, yaitu Rothmann (vol.

34) "Job satisfaction, occupational stress, burnout and work engagement as components of work-related" menjelaskan hasil penelitiannya bahwa berdasarkan hasil statistik dimensi exhaustion dan cynicism, vigor dengan dedication signifikan dengan kepuasan kerja.

Dimensi absorption pada penelitian ini memiliki pengaruh yang signifikan terhadap kepuasan kerja, hal ini sesuai dengan penelitian yang dilakukan oleh Oncer Zehra (2012) yaitu pada hasil penelitian nya menunjukkan kepuasan kerja memiliki hubungan positif yang kuat dengan totalitas kerja, begitu juga dengan sebaliknya totalitas kerja berpengaruh signifikan terhadap kepuasan kerja. Artinya, karyawan yang lebih tinggi memiliki rasa puas pada pekerjaannya, semakin terlibat juga pada pekerjaannya. Pada penelitian Oncer Zehra (2012) juga dijelaskan bahwa kepuasan kerja memiliki hubungan yang signifikan terhadap vigor, dedication dan absorption. Ketika driver gojek menyukai dan menghargai pekerjannya, maka tingkat kepuasannya juga akan tinggi karena apa yang mereka harapkan di dalam pekerjaannya dapat terpenuhi, dengan cara berdedikasi tinggi pada pekerjaannya, mempunyai semangat yang tinggi ketika mencari pelanggan untuk mencapai bonus harian yang akan didapatkannya. 
Pada variabel modal psikologis dalam penelitian ini dimensi resiliensi memiliki pengaruh yang signifikan terhadap kepuasan kerja. Hasil ini sesuai dengan penelitian terdahulu yang dilakukan oleh Youssef dan Luthans (2007) yaitu pada penelitiannya menunjukkan bahwa terdapat hubungan positif antara resiliensi dengan kepuasan kerja. Resiliensi pada driver sangat penting untuk dimiliki, karena dengan memiliki resiliensi, driver gojek dapat bertahan dalam pekerjaannya walaupun banyak sekali masalah yang dihadapinya.

Hubungan antara optimis dengan kepuasan kerja dapat membantu kesulitan dalam lingkungan kerja driver gojek untuk mencapai target. Kondisi kerja driver gojek juga dapat membantu terciptanya rasa optimis pada diri driver, ketika adanya rasa optimis lalu didukung dengan harapan, maka akan timbul kepuasan kerja. Memiliki harapan dalam pekerjaan dapat membantu memberikan rasa semangat ketika melakukan pekerjaan, driver juga akan bersungguh-sungguh dalam melakukan pekerjaannya.

Pada hasil penelitian dimensi efikasi diri tidak terdapat hubungan yang signifikan terhadap kepuasan kerja. Penelitian ini didukung oleh penelitian sebelumnya Bickes \& Kaplan (2012) menyatakan bahwa variabel efikasi diri tidak berpengaruh signifikan terhadap kepuasan kerja. Penelitian Yen-Chun Chen (2012) mengatakan bahwa hasil penelitiannya mengenai efikasi diri atau self efficacy berpengaruh positif terhadap kepuasan kerja. Artinya karyawan dengan efikasi diri yang tinggi memiliki kemampuan performa yang tinggi setelah memperoleh peningkatan kepuasan kerja pada dirinya.

Penelitian yang dilakukan Erdil (2012) menghasilkan hubungan yang signifikan antara variabel efikasi diri, totalitas kerja dan kepuasan kerja. Efikasi diri dapat menunjukkan apakah driver mampu atau tidaknya dalam mengatasi keadaan dalam pekerjaannya. Semakin tinggi efikasi yang dimiliki pada diri driver, semakin tinggi juga rasa percaya diri bahwa driver mampu dan akan berhasil dalam tujuan yang akan dicapai. Sedangkan pada penelitian ini, efikasi diri tidak berpengaruh dengan kepuasan kerja, hal itu dapat terjadi karena tidak adanya harapan dan sikap optimis pada diri driver. Tetapi, driver masih memiliki ketangguhan dalam menjalankan tugasnya dengan resiliensi yang tinggi pada dirinya. Secara keseluruhan, penulis menemukan adanya perbedaan hasil penelitian ini dengan penelitian terdahulu. Hal ini terjadi dikarenakan adanya beberapa keterbatasan atau kelemahan dalam penelitian, antara lain responden yang kurang telititi dan serius saat mengisi skala sehingga respon menjadi tidak berpola, atau kondisi dan situasi pada saat responden mengisi skala yang tidak kondusif serta banyaknya item dan tidak semua item mencakup konsep yang bisa dimengerti secara jelas oleh responden.

\section{Saran}

Penulis menyarankan untuk penelitian selanjutnya agar meneliti dan menganalisis pengaruh variabel eksternal seperti iklim organisasi dan variabel lain seperti ocb, komitmen organisasi dan beban kerja, sehingga didapatkan proporsi varians yang lebih tinggi dibandingkan dengan penelitian ini. Kemudian pada penelitian ini ditemukan terdapat dua variabel yang memiliki pengaruh signifikan terhadap kepuasan kerja, yaitu absorption dan resiliensi sehingga penulis menyarankan agar variabel tersebut dapat dijadikan referensi dalam penelitian 
selanjutnya. Penulis juga menyarankan, untuk penelitian selanjutnya untuk meneliti selain kepuasan kerja pada driver gojek. Selanjutnya penulis menyarankan untuk mencari sampel lain misalnya pada bagian HRD gojek, pimpinan dan karyawan tetap yang berada di kantor gojek, sehingga didapatkan hasil yang bervariasi dan dapat dijadikan pembanding dengan penelitian ini.

\section{DAFTAR PUSTAKA}

Ahmed, A. M. (2012). The Role of Self-esteem and Optimism in Job Satisfaction among Teachers of Private Universities in Bangladesh. Asian Business Consortium, Vol.1 (1).

Ali, J. A. (2008). Islamic Work Ethic: A Critical Review. Cross Cultural . Cross Cultural Management: An International Journal , Vol 15 (1). 5-19. DOI 10.1108/13527600810848791.

Arnold B. Bakker, E. D. (2008). Towards a model of work engagement. Career Development International, 13 (3). 209-223.

Badran, A. C. (2015). Psychological capital and job Satisfaction in Egypt. Journal of Managerial Psychology, Vol.30 (3) 354-370.

Bakker, A. D. (2008). Towards a Model of Work Engagament. Career Development International.

Chen-Chun, Y. \&. (2012). Self-Efficacy, Effort, Job Performance, Job Satisfaction, and Turnover Intention: The Effect of Personal Characteristics on Organization Performance . International Journal of Innovation, Management and Technology, Vol. 3 (4).

Denito, H. P. (2014). Job Satisfaction of Nurses: The Roles of Goal Congruence and Work Engagement. Management Dyanamics Conference. Semarang.

Greenberg, J. \&. (2003). Behavior in Organizations ( Understanding and Managing The Human Side of Work).

Kahn, W. A. (1990). Psychological Conditions of Personal Engagement and Disegagement at Work. Academy of Management Journal, 692.

Kalvina, A. (2016). Exploring the Relationships between Job Satisfaction, Work Engagement and Loyalty of Academic Staff. International Journal of Social, Behavioral, Educational, Economic, Business and Industrial Engineering, Vol.10 (1).

Kaplan M, \&. D. (2013). The Relationship Between Psychological Capital and Job Satisfaction: A Study of Hotel Businesses in Nevşehir. Yönetim ve Ekonomi , 233242.

Locke, E. (1969). Organizational Behavior and human Performance What is Job Satisfaction? American Institute for Research and Department of Psychology Unviversity of Maryland. Academic Press Inc., 303-336.

Luthans, F. A. (2010). The Development and Resulting Performance Impact of Positive Psychology Capital. Human Resource Development Quarterly, Vol. 21 (1).

Luthans, F. C. (2007). Psychological Capital Developing The Human Competitive Edge. New York: Oxford University Press.

Luthans, F. d. (2007). Positive Psychological Capital: Measurement and Relationship With Performance and Satisfaction. Leadership Institute Faculty Publication, 11.

Maharaj, A. S. (2014). Work Engagement, Intrinsic Motivation and Job Satisfaction among Employees of a Diamond Mining Company in Zimbabwe . Journal of Economics and Behavioral Studie, Vol. 6 (6). 488-499. 
Masvaure, P. R. (2014). Work Engagement, Intrinsic Motivation and Job Satisfaction among Employees of a Diamond Mining Company in Zimbabwe. Journal of Economics and Behavioral Studies.

Mustafa Yakin, O. E. (2012). Relationship between self-efficacy and work engagement and the effects on job satisfaction: A survey on certified public accountants. Procedia- Social and Behavioral Sciences, 370-378.

Oncer, Z. A. (2012). The Role of Self-Concept On The Relationship Between Employees' Perception of Job Satisfaction and Work Engagement. Global Review and Business and Economic Research, Vol. 8 (2). 207-220.

Pedhazur, E. J. (1982). Multiple regression in behavioral research: Explanation and prediction second edition. USA: CBS Collage Publishing.

Prihatsanti, U. (2010). Hubungan Kepuasan Kerja dan Need For Achievment Dengan Kecenderungan Resistance To Change Pada Dosen UNDIP Semarang. Jurnal Psikologi Undip, Vol 8 (2).

Rich, B. \&. (2010). Job Engagament: Antecedents and Effects On Job Performance. Academy of Management Journal.

Robbin, P. S. (1996). Organizational Behavior. Concept Controversies Applications.

Robbins, P. S. (2001). Perilaku Organisasi. Salemba Empat.

Rothmann, S. (n.d.). Job satisfaction, occupational stress, burnout and work engagement as components of work -related wellbeing. Journal of Industrial Psychology, Vol.34 (3). 11-16.

Salangka, R. D. (2015). Pengaruh Self Efficacy, Self Esteem dan Lingkungan Kerja Terhadap Kepuasan Kerja Karyawan Pada PT. PLN (PERSERO) Wilayah Suluttenggo. Jurnal EMBA, Vol 3. (3). 562-572.

Schaufeli, W. B. (2003). UWES- Utrecht Work Engagement Scale: Test Manual. Departement of Psychology. Utrecht University.

Schaufeli, W. B. (2004). Job demands, job resources, and their relationship with burnout and engagement: a multi-sample study. Journal Of Organizational Behavior, 25, 293315. DOI: $10.1002 /$ job. 248

Schaufeli, W. S. (2002). The Measurement of Engagament and Burnout: A Two Sample Confirmatory Factor Analytic Approach. Journal of Happiness Studies, 3: 71 - 92.

Sinambela, P. L. (2016). Manajemen Sumber Daya Manusia: membangun tim kerja yang solid untuk meningkatkan kinerja. Jakarta: Bumi Aksara.

Silen, P. A. (2016). Pengaruh Modal Psikologi dan Keterlibatan Pegawai terhadap Kinerja Pegawai dengan Kepuasan Kerja. Jurnal Manajemen Teori dan Terapan.

Sutisno, Edy, H. M. (2009). Manajemen Sumber Daya Manusia . Jakarta: Prenadamedia Group.

Spector, P. (1985). Measurement of Human Service Staff Satisfaction: Development of The Job Satisfaction Survey. American Journal of Community Psychology, Vol.13 (6).

Spector, P. E. (1997). Satisfaction Application, Assessment, Cause and Consequences. International Education and Professional: Sage Publication.

Tampubolon, S. M. (2013). The Effects of Leadership Style, Work Environment and The Lectures Expectation On Job Satisfaction In University. Jurnal Pendidikan dan Kebudayaan, Vol 19 (2).

Xanthopoulou D, B. A. (2009). Reciprocal Relatiosnhip Between Job Resources, Personal Resources and Work Engagament. Journal of Vocational Behavior, Vol.74 (3) p.235244.

Youssef, C. M. (2007). Positive Organizational Behavior in the Workplace: The Impact of Hope, Optimism and Resilience. Journal of Management, Vol.36. 11-23. 